\title{
Effects of Direct Water Injection on DI Diesel Engine Combustion
}

\author{
F. Bedford and C. Rutland \\ Engine Research Center, UW-Madison
}

\author{
P. Dittrich, A. Raab and F. Wirbeleit \\ DaimlerChrysler Research
}

Copyright (@ 2000 Society of Automotive Engineers, Inc.

\begin{abstract}
The effects of in-cylinder water injection on a direct injection (DI) Diesel engine were studied using a computational fluid dynamics (CFD) program based on the Kiva-3v code. The spray model is validated against experimental bomb data with good agreement for vapor penetration as a function of time. It was found that liquid penetration increased approximately $35 \%$ with $23 \%$ of the fuel volume replaced by water, due mostly to the increase in latent heat of vaporization.
\end{abstract}

Engine calculations were compared to experimental results and showed very good agreement with pressure, ignition delay and fuel consumption. Trends for emissions were accurately predicted for both $44 \%$ and $86 \%$ load conditions. Engine simulations showed that the vaporization of liquid water as well as a local increase in specific heat of the gas around the flame resulted in lower Nitrogen Oxide emissions (NOx) and soot formation rates. Using stratified fuel-water injection increases soot at $86 \%$ loads due in part to late injection. Because NOx decreased at all loads, the injection timing can be advanced to minimize fuel consumption and soot.

\section{INTRODUCTION}

Recent fluctuations in fuel prices have underscored some of the pressures under which the engine industry operates. In many industries, fuel economy is a primary concern, yet health risks from high concentrations of airborne toxins cannot be ignored. Thus, constraints from legislating bodies combine with market forces to push engine manufacturers towards creating engines that simultaneously use less fuel and produce fewer harmful pollutants. Techniques such as split injection, high pressure fuel injection (see Han [4] and Reitz [9]), and stratified fuel-water in cylinder injection (see Wirbeleit [12] and Takasaki [10]) have been shown effective at reducing pollutants from DI Diesel engines while minimizing fuel consumption. This paper describes a computational study of stratified Direct Water (DW) injection. Here we use CFD to explore the effects of DW injection on Diesel engine combustion to gain insight into the in cylinder processes which make the technique one of the most promising technologies for NOx reduction.

There are several practical means of inducing water into the combustion chamber (see Wirbeleit [12]). Fumigation, emulsions, parallel injection systems and DW injection are all effective realizations of water injection technology, each with their own set of advantages and drawbacks. In this study, it must be stressed that the fuel and water are separate until just before the actual injection event - DW injection is not an emulsion and does not suffer from the same drawbacks.

Fumigation is where liquid water is injected into the intake manifold upstream of the intake valve. The fumigation technique has been shown to reduce NOx emissions in DI Diesel applications but suffers from the drawback that the liquid water in the combustion chamber is typically in areas where it is less effective at reducing emissions. Therefore, fumigation requires approximately twice the liquid volume for the same reduction in engine out NOx when compared to DW injection. Additionally, liquid water present after combustion can contaminate the oil and increase engine wear.

Emulsified fuel-water blends can be used as an alternative fuel and have been shown to reduce NOx and particulate matter (PM) emissions. However, emulsified fuel blends tend to lower the combustion temperature indiscriminately. Lower temperatures too early in combustion can lead to increased ignition delay and engine noise. Although there is little or no increase in engine cost when using emulsified fuels, the engine 
injection timing must be changed to take advantage of the new mixture. A more significant drawback to emulsified fuels is that the percentage of water is constant and cannot be changed for cold start or other transient operating conditions. In other words, a particular blend of fuel and water may be optimal for one operating condition but degrade performance for other points in the design envelope.

DW injection has the advantage over fumigation of having the liquid water close to the flame and away from the wall. Unlike emulsified fuels, DW injection allows the fuel-water percentage to be changed for cold start or different operating ranges. Although the injection system needs to be modified for DW injection, a single injector per cylinder is used so that the overall cost would be less than a parallel injection system. A schematic of a typical dual feed injector is shown below in figure 1 .

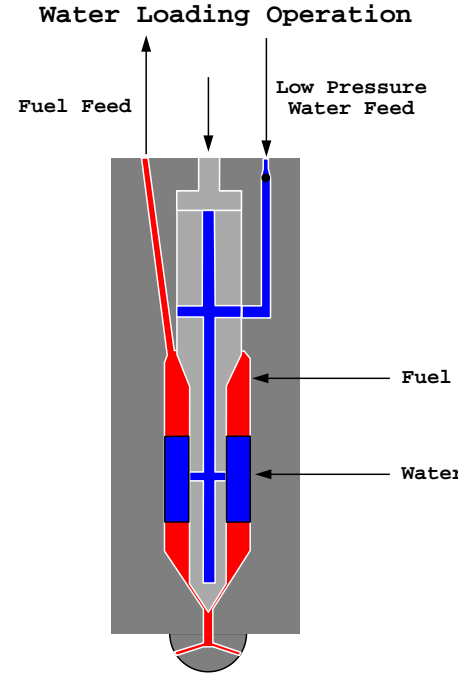

a)
Fuel Injection Operation

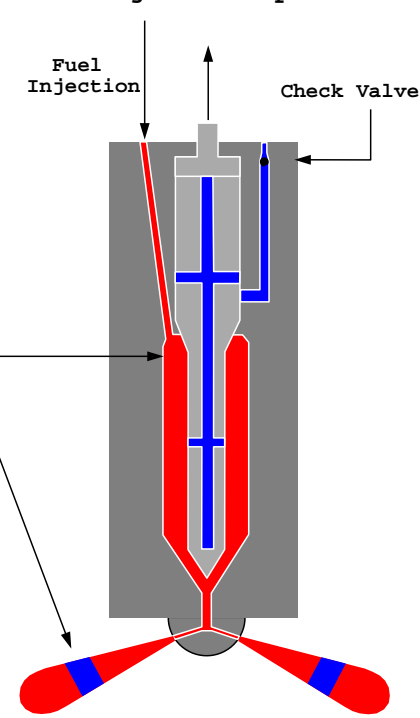

b)
Figure 1: Operation of a typical Fuel-Water Injection system.

The key to the DW injection system is the dual feed injection nozzle with the corresponding water supply system. Note that the water supply system does not need to support high pressures like the fuel injection system. The water loading event (Figure 1a) shows the water being pushed first through a one-way valve, then through the hollow passage in the injector body and eventually into the annular sac region surrounding the central pintle valve. The fuel displaced by the water is returned to the fuel injection pump.

At the start of the injection event, the pressure in the fuel line is increased which closes the one-way valve so that no fuel contaminates the water line. The fuel-water mixture is forced out of the injector by the high pressure fuel. The amount of mixing inside the injector is not well known and can vary with the design of the injector body. Typically, a larger volume of the secondary chamber in the injector allows more mixing of fuel and water to occur before the injection event and a smaller chamber (with less fuel in front of the water slug) allows less mixing. As will be seen in the engine calculation section, having the water towards the front of the injection causes significant ignition delay.

\section{NUMERICAL MODELING}

A modified version of the KIVA-3v (see Amsden [1]) CFD program, originally developed at Los Alamos National Laboratory, was used for this study. KIVA solves the conservation equations for unsteady, compressible, turbulent reacting flows on finite volume grids. There have been numerous additions and modifications of many submodels at the ERC and DaimlerChrysler Research that have been validated for engine combustion simulations. The additional submodels have been described in the literature and so are only briefly mentioned below (see Rutland [8] and Dittrich [3] for details). The multidimensional simulations for Diesel engine combustion have been extensively verified with modern optical experimental methods in high temperature combustion bombs as well as in transparent single cylinder engines (see Schwarz [11]).

The standard $k-\varepsilon$ model was used to account for turbulence, and the spray breakup is computed with the "wave" breakup model of Reitz [7] which has been modified to account for the effects of drop distortion on the drag coefficient of the drops (see Han [4]). For this study, the new parcel diameter is calculated using an SMR conserving breakup concept (from Patterson [6]). Ignition delay is modeled with a Wolfer type equation for the ignition delay which takes into account the local equivalence ratio, pressure and temperature (see Dittrich [3]).

Using a Wolfer type equation for ignition delay in the presence of water seems to capture the effects of temperature and pressure adequately. As a check, constant pressure oxidations of $n$-heptane with varying amounts of initial water vapor were calculated using a detailed chemical kinetic mechanism of 550 species and 2450 reactions (see Curran et.al. [2]) using the CONP program from Chemkin II. At an equivalence ratio of 1 , 86 bar initial pressure and $900 \mathrm{~K}$ initial temperature, a $140 \%$ water/fuel vapor mass ratio increased the ignition delay less than half a millisecond, or less than half a crank angle at the engine speed considered. Higher equivalence ratios were even less sensitive to additional water vapor. Thus, the effect of water vapor was not explicitly included in the ignition correlation. Since other operating points could show more significant changes in ignition delay in the presence of large amounts of water vapor, the correlation could be modified for future studies. 


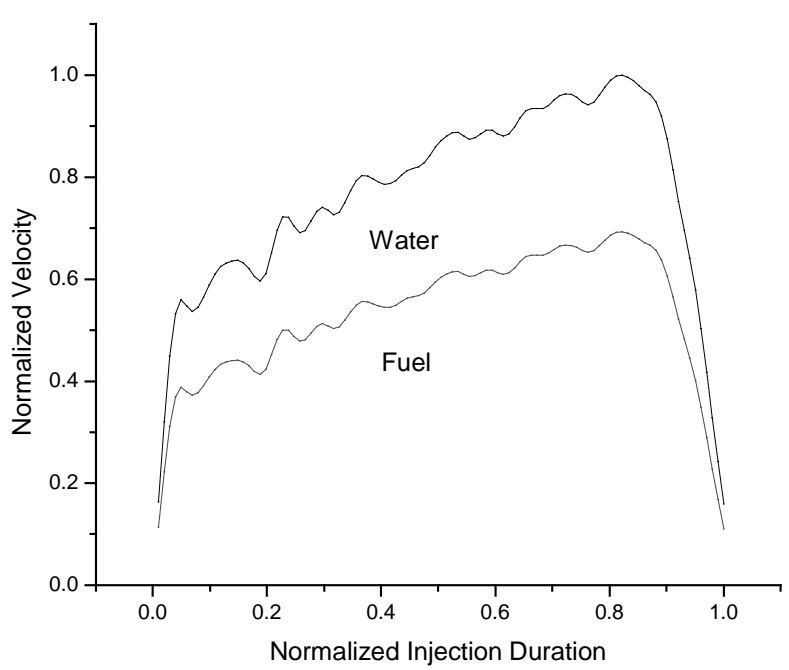

Figure 2: Distribution of water in the fuel spray for a wide distribution function $\left(\sigma_{w}=5.00\right.$ and $\left.x_{c}=0.5\right)$.

Combustion is modeled with the seven species characteristic time model that is explained in detail in Patterson [6] and Han [4]. Emissions of nitrogen oxides (NOx) are modeled with the extended Zel'dovich mechanism and soot is modeled with the Hiroyasu model. Detailed descriptions of the implementation of the current models are available in papers by Han [4] and Kazakov [5].

Including the effects of a second liquid species required extensive modification to the existing subroutines. The two liquids are always separate and no mixing is allowed in during the collision process, however the species do interact in the gas phase. Treating the liquids separately allows modeling of parallel injection systems as well as typical single nozzle (multiple hole) injection systems.

When modeling one multiple hole injector, the fuel and water are injected from the same spatial location and the velocity profile is calculated using the sum of the fuel and water masses. The water mass is added to the fuel mass and the velocity profile accordingly scaled.

The water distribution in the spray is biased by the following Gaussian function

$$
p(x)=A \exp \left(\left(x-x_{c}\right)^{2} / \sigma_{w}\right)
$$

where $p(x)$ is the probability of finding a water parcel in the fuel spray. The normalization constant $A$ is chosen so that the fuel/water mass ratio is correct, the center of the Gaussian is denoted $x_{c}$ and the width is given by $\sigma_{w}$. If the distribution function causes the spray mass to go

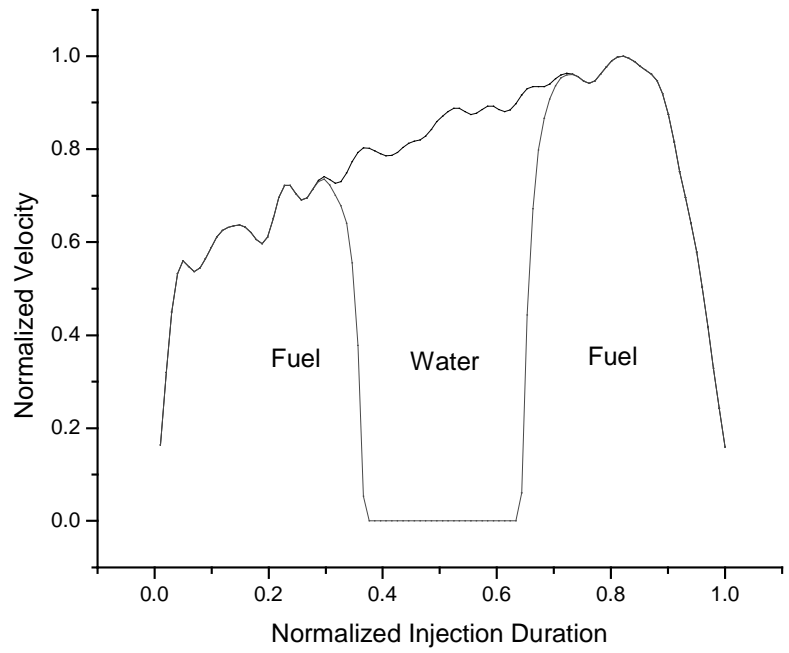

Figure 3: Distribution of water in the fuel spray for a narrow distribution function $\left(\sigma_{w}=0.05\right.$ and $\left.x_{c}=0.5\right)$.

too high, the function is clipped and rescaled to ensure mass conservation. By clipping the top of the Gaussian distribution function, the water in the spray can completely displace the fuel in that portion of the injection. A small value for $\sigma_{w}$ implies a narrow, high distribution with sharp stratification of fuel and water, while a large value for $\sigma_{w}$ implies a uniform mixing of the fuel and water inside the injector.

An example of a wide distribution is shown in Figure 2 for parameter values of $\sigma_{w}=5.00$ and $x_{c}=0.5$ with $45 \%$ of the fuel mass was input as water. A velocity distribution for a narrow distribution function $\left(\sigma_{w}=0.05\right)$ is shown in Figure 3 for the same $45 \%$ fuel/water ratio.

For the engine cases, the fuel consumption values were calculated in Kiva by integrating $\mathrm{p} d \mathrm{~V}$ from intake valve closing to exhaust valve opening to obtain an IMEP value and dividing the result by the fuel injected in the cycle.

\section{SPRAY MODEL VALIDATION}

Experiments for Diesel fuel/water injection were performed with a prototype Bosch dual feed injector, where the stratification of the fuel and the water can be controlled. In this study, the volumetric flow rate was kept constant. In each case, $136 \mathrm{~mm}^{3}$ of liquid was injected into a quiescent chamber filled with Nitrogen at $830 \mathrm{~K}$ and 41 bar. The spray was illuminated from below by a laser sheet and vapor penetration was obtained by fluorescence. More detail on the experimental setup can be found in Renner [9]. 


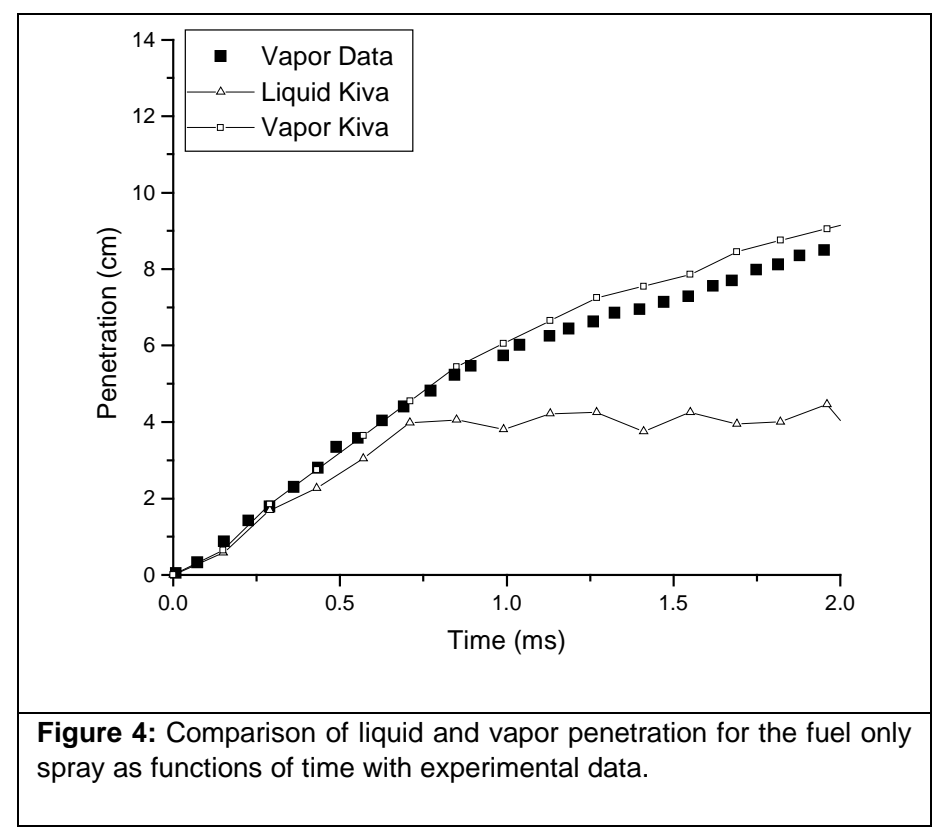

For the spray considered, the nozzle diameter is $345 \mu \mathrm{m}$ and the injection duration is $1.7 \mathrm{~ms}$. Peak injection pressures varied from 600 to 800 bar depending on the composition of the spray and injection duration. Because the magnitude of the mixing inside of the injector was not known, the spray was considered as uniformly mixed $\left(\sigma_{\mathrm{w}}=5.0\right)$.

In the experimental study, the volume injected was held constant and the composition varied by feeding water into a secondary annular chamber inside the fuel injector. For the water case, $77 \% \quad\left(105 \mathrm{~mm}^{3}\right)$ of the injected volume was fuel and the remaining $23 \%\left(31 \mathrm{~mm}^{3}\right)$ was water. The mesh spacing was chosen to be close to that used in typical engine calculations.

The total number of parcels injected was 500 , which was sufficient for accuracy in this two-dimensional simulation. The number of parcels in the course of the calculation varied due to differences in breakup and evaporation rates for the different sprays. Typically, the cases where water was injected had a higher number of parcels, despite an identical number of total injected parcels. This computational study used a representative Diesel fuel, $\mathrm{C}_{14} \mathrm{H}_{30}$, and $\mathrm{H}_{2} \mathrm{O}$ as the two liquids. The fuel species, $\mathrm{C}_{14} \mathrm{H}_{30}$ was chosen because it has physical properties that are close to an average Diesel fuel. For these calculations, a model constant proportional to the breakup time was changed to characterize the injector for the fuel only spray. This same constant was used for both the water and fuel injectors for subsequent calculations.

The liquid penetration values were defined in the computation as the minimum distance along the injection direction that includes $95 \%$ of the liquid mass.

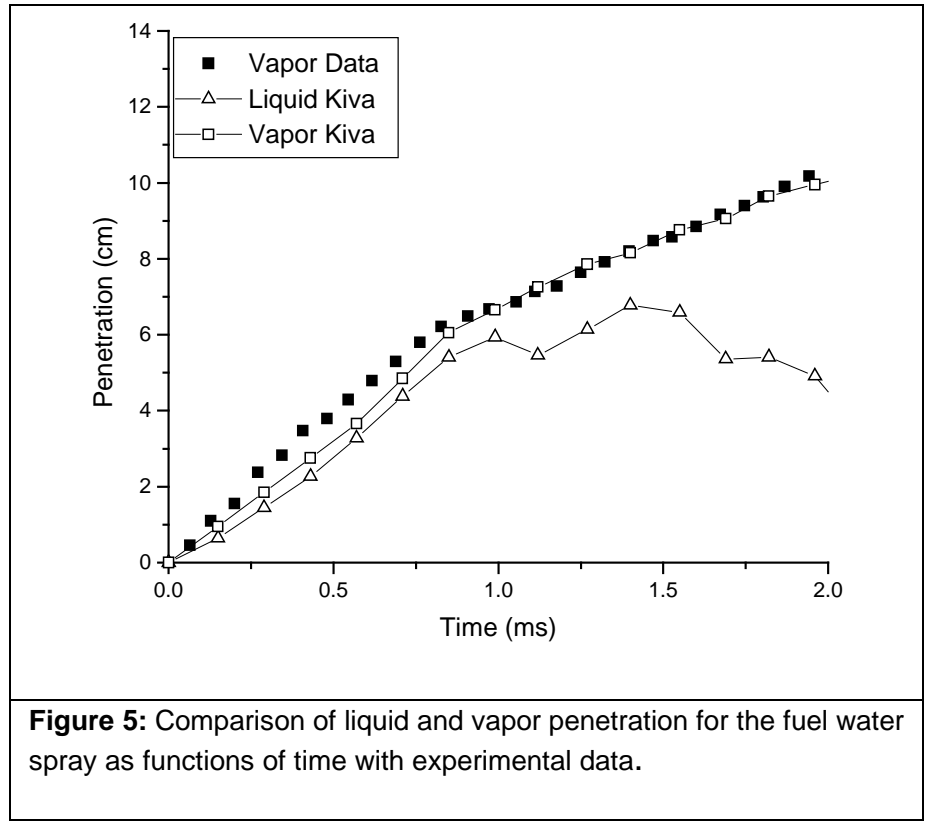

The vapor penetration was defined as the point along the injection direction nearest the tip where $5 \%$ of the maximum vapor concentration occurs. In all simulations, the liquid and vapor penetrations split from each other, the liquid penetration reaching a plateau of between 4 and $6 \mathrm{~cm}$ while the vapor continued to penetrate.

Figures 4 and 5 show a comparison of the experimental vapor penetration to the calculated vapor penetration and also show the calculated liquid penetration, all as functions of time. For these calculations, the calculated vapor penetration is very close to the experimentally measured values. For this injector, which produces relatively large drops, the vapor and liquid penetrations were very similar initially, but diverged from each other when the jet penetrated about $4 \mathrm{~cm}$ from the nozzle for the fuel only spray.

The presence of water in the fuel spray increases both the liquid and vapor penetration, however the liquid penetration is changed more significantly as shown in Figure 5. As can be seen from the comparison of calculated spray tip penetrations in Figures 4 and 5, the water lengthens the liquid penetration at $150 \mathrm{~ms}$ by approximately $35 \%$ when $23 \%$ of the injected liquid is water.

Note that the vapor penetration is not changed as much as the liquid penetration when water is added to the spray, in fact most of the difference can be attributed to the additional momentum from the increased density of the water vapor. 


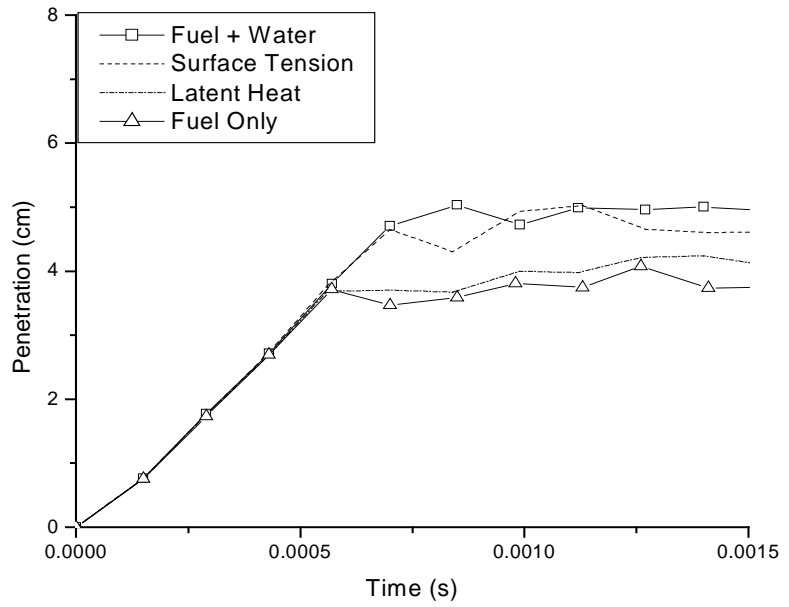

Figure 6: Liquid Penetration vs. Time - Sensitivity to Physical Properties

To gage the relative importance of the physical parameters of the second injected liquid (e.g. water), the physical properties of the injected water were selectively changed to equal those of the fuel. The liquid penetration as a function of time of the modified spray is shown in figure 6 .

When the surface tension of the water is set equal to the fuel, the Weber number of the liquid water increases which shortens the breakup time of the water spray. The effect of the water fades more rapidly when the water breaks up sooner, and approximately $15 \%$ of the original liquid penetration distance is recovered at $1.5 \mathrm{~ms}$.

The effect of higher liquid latent heat is that more energy is required to vaporize the spray. The liquid persists for a longer time and travels further into the domain. Additionally, the vaporization rate of the overall spray per unit volume decreases due to the lower temperature from the water vaporization. Thus, one would expect a high sensitivity of liquid penetration to latent heat effects.

Figure 6 shows the effect of changing the latent heat of vaporization of the water equal to that of the fuel. When the latent heats of the two liquids are set equal, nearly $85 \%$ of the original liquid spray penetration is recovered. As a check on the model, when the physical properties of the second liquid are set equal to the first liquid, the original penetration is recovered.

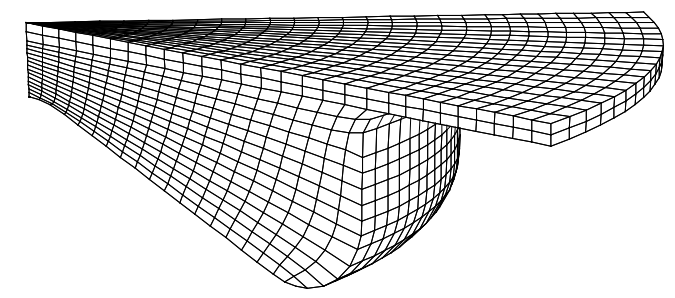

Figure 7: Computational mesh at $\mathrm{CA}=0.0$.

If a highly stratified distribution is used the effects of the water are isolated in that section of the injection. If the water is biased towards the front of the spray, both liquid and vapor fuel penetrate further because the gas is already moving when the fuel is injected. When the water slug is biased towards the end of the spray, fuel towards the end of the injection penetrates further.

\section{ENGINE RESULTS}

The combustion models have been validated by Dittrich [3] and Schwarz [11] in a number of studies of DaimlerChrysler heavy-duty diesel engines. Specifications and operating conditions are given in Table 1. The computational mesh for the engine simulations is shown in Figure 7. At TDC, there are 25 cells in the radial direction, 14 cells in the vertical direction (perpendicular to the piston) and 20 cells in the azimuthal direction. The injector is a centrally located, 8hole common rail type which is modeled as a 45 degree sector with the parcels initially entering the domain at the vertex of the sector mesh.

Table 1: Engine Parameters

\begin{tabular}{|c|c|}
\hline Parameter & Value (units) \\
\hline Bore & $13.00(\mathrm{~cm})$ \\
\hline Stroke & $15.00(\mathrm{~cm})$ \\
\hline Connecting Rod Length & $27.3(\mathrm{~cm})$ \\
\hline Displacement & $2.00($ Liters) \\
\hline Compression Ratio & 17.25 \\
\hline Engine Speed & $1080(\mathrm{rev} / \mathrm{min})$ \\
\hline Start of Injection & -2 ATDC \\
\hline
\end{tabular}




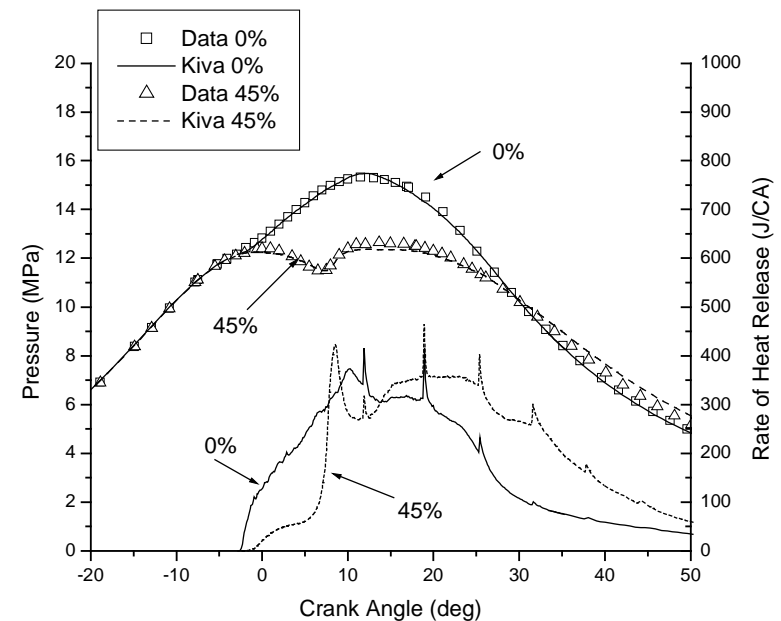

Figure 8: Comparison of the $86 \%$ load simulation with experimental pressure data (top) for $0 \%$ and $45 \%$ and predicted heat release rate (bottom) for $0 \%$ and $45 \%$ water/fuel ratio.

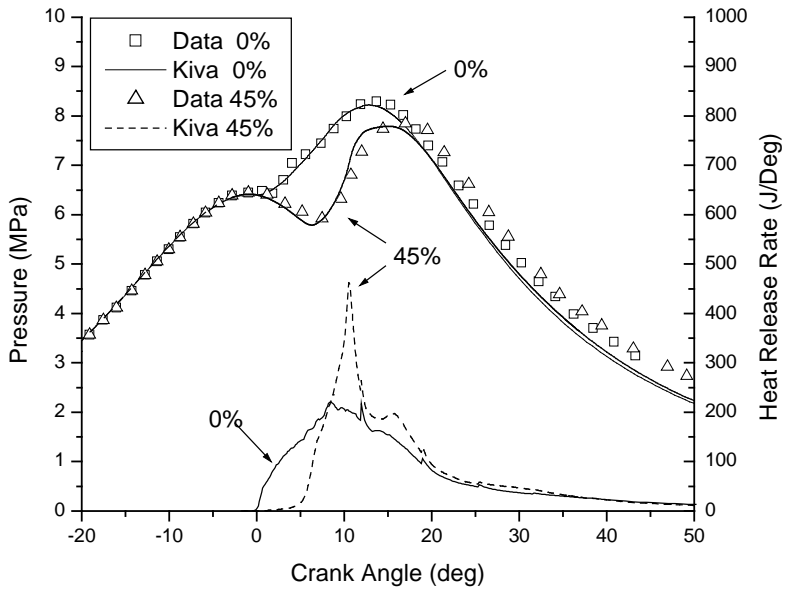

Figure 9: Comparison of the 44\% load simulation with the experimental cylinder pressure (top) and predicted heat release rate (bottom) for $0 \%$ and $45 \%$ water/fuel ratio.

\section{Comparison of Engine Model to Experiments}

Opposing trends for fuel consumption and soot production are observed experimentally for the $86 \%$ and $44 \%$ load points as the water/fuel ratio increases. At $44 \%$ load conditions, engine out soot, engine out NOx and specific fuel consumption (SFC) decrease with increasing water percentage. At $86 \%$ load conditions, engine out soot and SFC increase with increasing water percentages, though engine out NOx values decrease with increasing water/fuel ratios. The simulations shed light on the underlying physical mechanisms responsible for these trends.

Both 86\% load and 44\% load cases showed considerable ignition delay when water was added to the spray. When the water in the injection is biased towards the front of the spray event, the evaporating water lowers the local temperature significantly for the initial fuel pulse and thus delays the ignition. The larger volume of liquid in the fuel-water spray requires increased injection duration to maintain the same volumetric flow rate. For each of the load points, parameters in the combustion model and the spray model were adjusted for the fuel only condition, but were not tuned for subsequent calculations.

The ignition delay was very sensitive to the water distribution parameters which shows the importance of the dynamics of the internal nozzle flow. The center and width of the water distribution in the fuel water spray were adjusted until the ignition delay was correctly calculated. In this way, the distribution of water inside the nozzle can be estimated.
Figure 8 shows the agreement between measured and computed cylinder averaged pressures and the computed rate of heat release for the $86 \%$ load condition for both $0 \%$ and $45 \%$ water/fuel ratio. The agreement with experimental pressure is very good, as is the agreement with the additional ignition delay due to water. For the $45 \%$ water case shown in Figure $8, x_{c}=0.135$ and $\sigma_{w}=0.180$ which resulted in an ignition delay of 8 crank angle degrees. For the $86 \%$ load case with $45 \%$ water, the injection duration increased about 6.5 crank angle degrees.

For the $86 \%$ load case, more heat is released later in the cycle and the cylinder pressure rises above the baseline condition after a crank angle of about 30 degrees after top dead center (ATDC). The peak pressure is also delayed in proportion to the ignition delay (about 8 crank angle degrees), but is reduced nearly $30 \%$ in magnitude. The premixed burn is intensified, as can be seen from the initial spike in the rate of heat release plot in Figure 8.

Figure 9 shows the agreement of the calculated cylinder pressures to the experimental cylinder averaged pressures for the $44 \%$ load condition with $0 \%$ and $45 \%$ water/fuel ratio. The calculation used water parameters of $\mathrm{x}_{\mathrm{c}}=0.120$ and $\sigma_{\mathrm{w}}=0.110$ which also displaced a significant portion of fuel from the first part of the injection. The injection duration increased 3 crank angle degrees and the ignition delay was approximately 6 crank angle degrees with a $45 \%$ water/fuel ratio. The peak pressure is delayed about 6 degrees from the fuel only case, however the magnitude of the peak pressure is only $10 \%$ lower. The premixed burn is intensified due to the delayed ignition. 


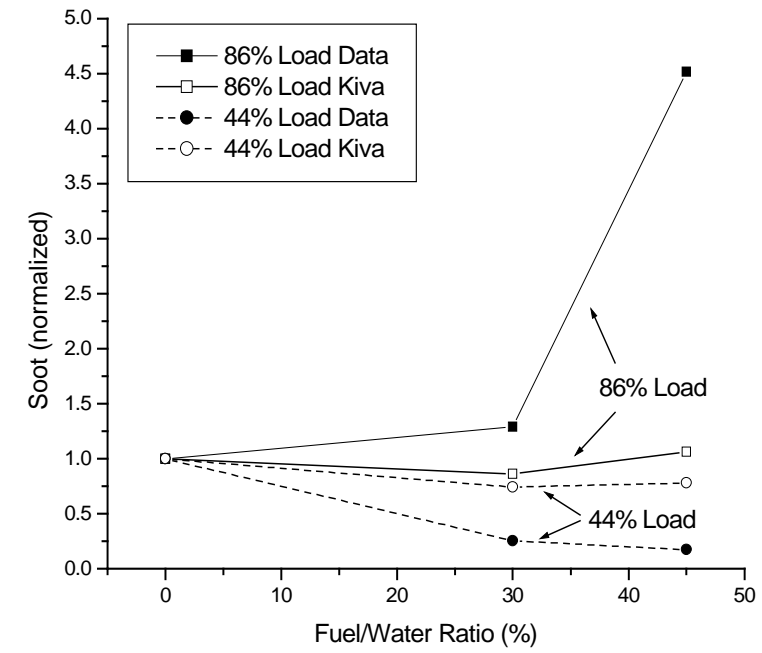

Figure 10: Soot vs. \%Water tradeoff curve for $86 \%$ and $44 \%$ load points for experiment and simulation

\section{Comparison to Engine Emissions and SFC Data}

Figure 10 shows the comparison of the computations with experimental engine out particulate emissions as a function of water percentage. The soot values were normalized by their baseline values for the sake of comparison. The comparison to experimental data shows that soot values at $86 \%$ load were underpredicted while the values at $44 \%$ load were overpredicted. The shape of the soot curves as a function of water/fuel ratio agrees well with the experiment.

Here, the soot is reduced for $44 \%$ loads and increases dramatically for $86 \%$ loads. Because the experiments measured opacity and the computations are based on engine out particulate emissions from dilution tunnel, the agreement in magnitude cannot be expected. The numerical soot model is also based on a purely empirical approach (see Han [4]) which does not include the effects of liquid water on soot production or oxidation. The kinetic rate constants of the soot model were not modified for water explicitly, however the model is sensitive to temperature effects.

Part of the explanation for increased soot production at the $86 \%$ load point is the increased injection duration from the additional liquid volume in the spray. This will be discussed in the next section.

Figure 11 shows the SFC vs. NOx tradeoff curve for the $44 \%$ and $86 \%$ load points. The numerical values are given in Table 2. The agreement with fuel consumption is good for both load points, and the agreement with NOx for the $44 \%$ load point is also good. Both NOx and SFC

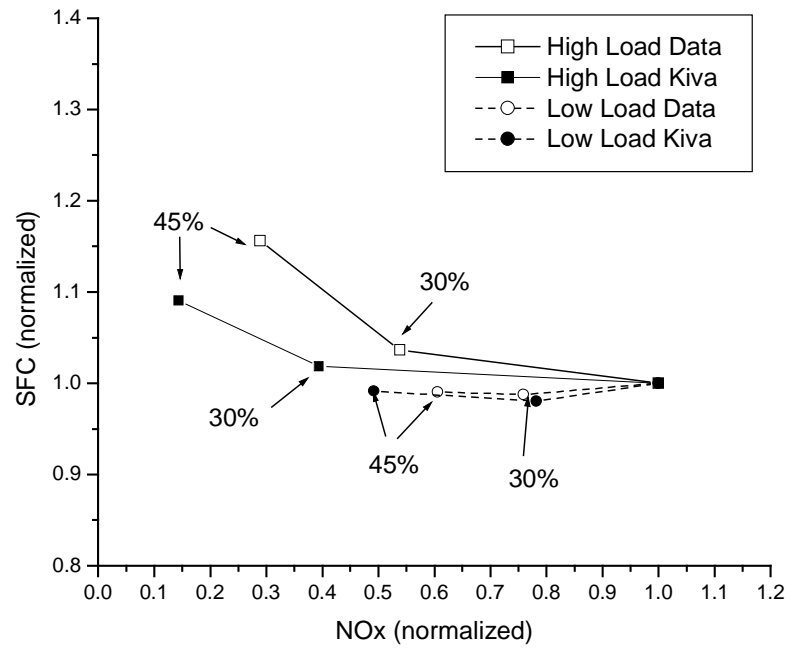

Figure 11: SFC vs. NOx tradeoff curve for $86 \%$ and $44 \%$ loads for the computations of the baseline, $30 \%$ and $45 \%$ fuel-water ratio simulations.

trends are well represented by the calculations at both loads. The calculated NOx reduction at the $86 \%$ load point is optimistic, and may possibly be due to suppressing on the thermal NOx mechanism without allowing other chemical pathways. This is an area of current research and will be the subject of future publications.

The reason behind the improved fuel economy for $44 \%$ load cases can be seen from Figure 9. The peak pressure decreased only $10 \%$ and the pressure is higher than the baseline after about 30 degrees ATDC, resulting in increased work output and a corresponding $1.0 \%$ improvement in SFC.

At $86 \%$ loads, SFC increases with increasing water/fuel percentage. Figure 8 shows a $30 \%$ reduction in peak pressure (for $45 \% \mathrm{~W} / \mathrm{F}$ ) which reduces the work output significantly. Although pressure later in the cycle is higher, the loss in work early in the cycle is too great to overcome and the SFC increases nearly $16 \%$.

Table 2: Changes in Emissions vs. W/F Ratio

\begin{tabular}{|l|c|c|c|c|}
\hline & NOx & (\%) & SFC & (\%) \\
\hline & Exp. & Comp. & Exp. & Comp. \\
\hline 44\% load & -24.1 & -21.8 & -1.2 & -1.9 \\
$30 \%$ W/F & & & & \\
\hline $\begin{array}{l}44 \% \text { load } \\
45 \% \text { W/F }\end{array}$ & -39.4 & -50.8 & -1.0 & -0.9 \\
\hline $\begin{array}{l}86 \% \text { load } \\
\text { 30\% W/F }\end{array}$ & -46.1 & -60.6 & +3.6 & +1.8 \\
\hline $\begin{array}{l}86 \% \text { load } \\
\text { 45\% W/F }\end{array}$ & -71.1 & -85.6 & +15.6 & +9.1 \\
\hline
\end{tabular}




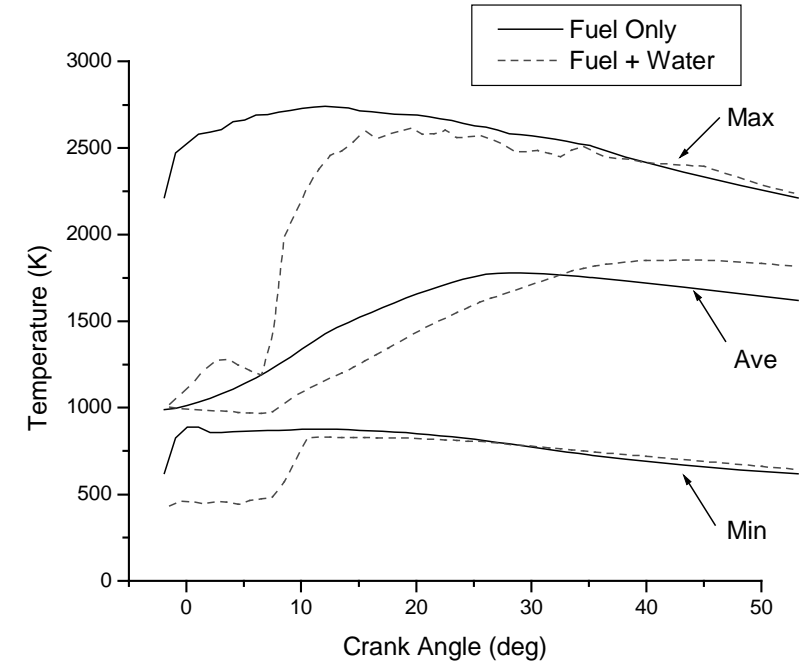

Figure 12: Calculation of maximum, minimum and average temperature inside the spray plume for the $86 \%$ load case and for the baseline and $45 \%$ fuel/water mixture.

\section{Comparison of Temperatures in Spray Plume}

To find the underlying mechanism behind the differences in pollutant production between the engine cases considered, the maximum, minimum and average temperatures were calculated inside the spray vapor plume. The vapor plume was calculated by finding the cells where carbon species were present and obtaining the necessary temperatures. For an initial condition including EGR, the criteria would be modified to consider the initial carbon element mass fraction. The volume of the carbon carrying species increases as a function of crank angle until the entire volume has some amount of carbon present either as $\mathrm{CO}_{2}$ or $\mathrm{CO}$ after crank angles of 80 degrees ATDC for the $44 \%$ load case.

Peak temperatures in the domain are reduced by two localized phenomena. First, vaporization of liquid water decreases the internal energy proportionally to the vaporization enthalpy of the liquid water. Secondly, higher concentrations of water vapor increase the specific heat of the gas. The reduced temperatures decrease the NOx formation rate and decrease the soot formation rate. Because there is no free oxygen displaced with DW injection (unlike EGR) soot oxidation rates are not adversely effected.

Figure 12 shows the results of the temperature calculation inside the spray plume for the $86 \%$ load condition. The peak temperatures inside the plume are reduced by approximately $100 \mathrm{~K}$ over the duration of the injection. This reduction in peak temperature greatly reduces the NOx production rate and also suppresses the soot production rate inside the combustion plume.

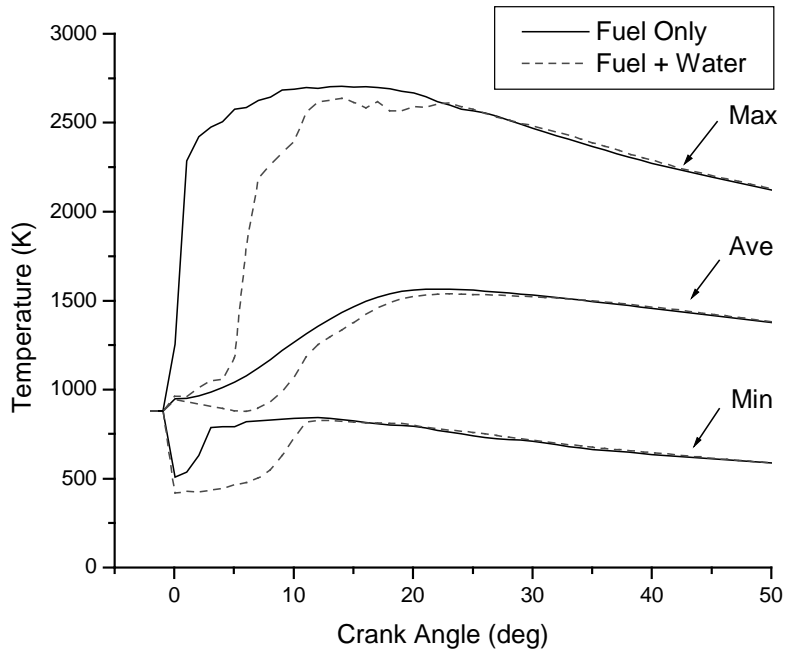

Figure 13: Calculation of maximum, minimum and average temperature inside the spray plume for the $44 \%$ load case and for the baseline and $45 \%$ fuel/water mixture.

Additionally, Figure 12 shows the mass averaged temperature inside the spray plume higher after a crank angle of about 30 degrees ATDC. The higher average temperatures are due in part to the later heat release from the combustion and also from an increase in mass from the vaporization of the liquid water.

Figure 13 shows the maximum, minimum and mass averaged temperature inside the spray plume as a function of crank angle for the $44 \%$ load condition. Again, the peak temperatures are reduced by over $75 \mathrm{~K}$ throughout the duration of the injection and stay below the baseline peak temperatures until a crank angle of 25 degrees ATDC. Unlike the $86 \%$ load condition, the average temperature is only slightly above the baseline for crank angles greater than about 30 degrees ATDC.

Despite the higher average temperatures after crank angles of 30 degrees ATDC with DW injection, the predicted NOx output is lower than the baseline for both load conditions. Some of the NOx reduction can be attributed to delayed injection timing, however most of the NOx reduction can be attributed to the lower local temperatures and higher local $C_{p}$ due to the vaporization of liquid water.

The effects of decreased soot formation and unchanged soot oxidation act in concert to decrease the overall engine out soot. The $86 \%$ load condition lengthened the injection duration by 6 crank angle degrees, which tends to increase engine out soot significantly. The presence of water decreases soot in both load cases, however not enough to compensate for late injection of fuel at the $86 \%$ load point. 


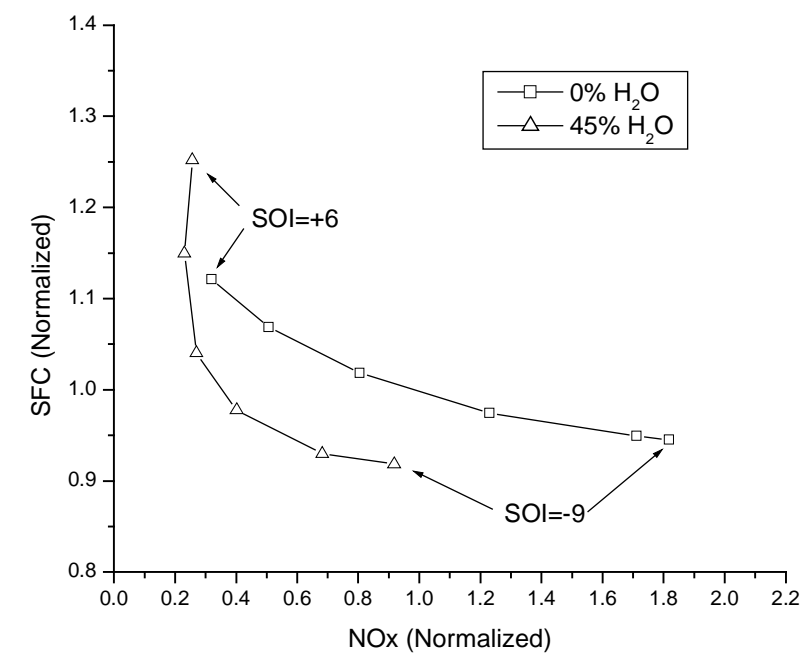

Figure 15: Simulated SFC/NOx tradeoff curves for injection timings of $-9,-6,-3,0,+3$ and +6 degrees ATDC for fuel only and $45 \%$ water/fuel ratio at the $44 \%$ load condition.

\section{Simulated Timing Sweeps}

To show the potential use of water injection to simultaneously reduce emissions and fuel consumption, simulated timing sweeps were performed at the two load points. Since water injection is highly effective at controlling NOx, the concept was to see if the NOx/SFC tradeoff could be improved using injection timing. The injection pressure, duration and water distribution parameters were kept the same as the previously verified load points. The curves in Figure 15 have all been normalized by the values for NOx and SFC of the $44 \%$ load baseline condition (SOI=-2 ATDC) for the sake of comparison. Similarly, curves in Figure 16 have been normalized by the NOx and SFC values of the $86 \%$ baseline condition (SOI $=-2$ ATDC).

Since the trends for NOx emissions and fuel consumption are well represented, the timing sweeps are a good representation of the potential for water injection to simultaneously reduce emissions and fuel consumption. To truly see the potential for DW injection, parameters such as injection duration and EGR rate should be optimized.

The curves in Figure 15 show the SFC/NOx tradeoff for the $44 \%$ load case. DW injection shifts the curves to the left by reducing both the NOx and the SFC for injection timings less than 0 degrees ATDC. Late fuel injection decreases NOx further, but the SFC increases more with DW injection due to late injection from the additional volume in the spray.

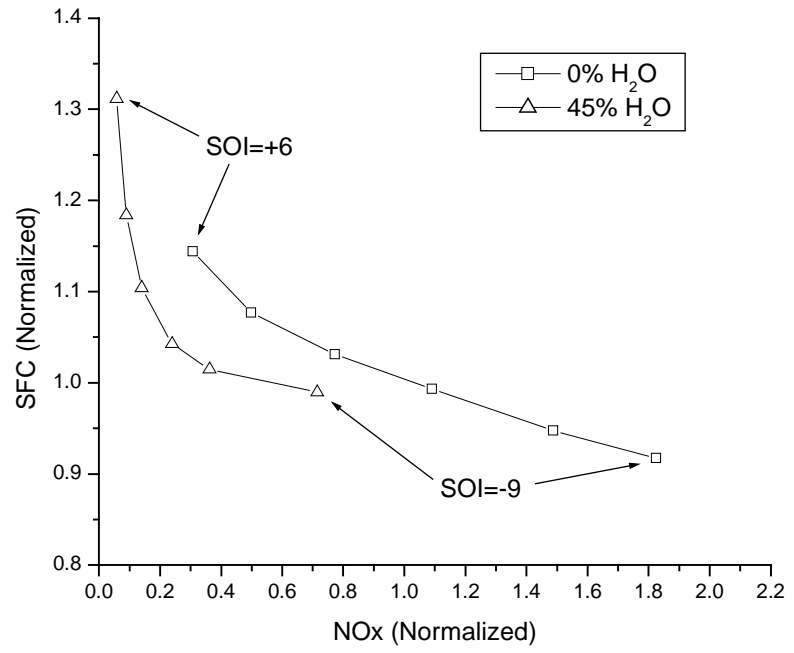

Figure 16: Simulated SFC/NOx tradeoff curves for injection timings of $-9,-6,-3,0,+3$ and +6 ATDC for fuel only and $45 \%$ water/fuel ratio at the $86 \%$ load condition.

The $44 \%$ load conditions show a marked decrease in engine out NOx for all injection timings. The best tradeoff between SFC and NOx is an SOI of -6 ATDC. The early injection decreases SFC markedly, however the $45 \%$ water/fuel spray decreases the NOx below what can be attained with shifting the injection timing to 0 ATDC without water injection.

Figure 16 shows the SFC/NOx tradeoff for the $86 \%$ load conditions. The high load case shows trends similar to the $44 \%$ load condition with respect to NOx - NOx is greatly decreased for all injection timings. Engine out soot for the $86 \%$ load cases increases due mostly to the late injection of fuel. Advancing the injection timing to compensate for the additional ignition delay with the fuel/water injection improves the soot output markedly, however limited gains are seen for SOI values greater than -6 .

For the $45 \%$ fuel/water mixture considered here, the best injection timing compromise for NOx and SFC for $86 \%$ loads is -6 ATDC. This timing produces less NOx than the latest injection $(+6)$ for the fuel only case, while not increasing the fuel consumption above the baseline timing condition.

For $44 \%$ loads, water injection has the potential to decrease SFC by about $8 \%$ by using an early SOI (-9 and -6$)$. For the $86 \%$ load condition, an early SOI combined with $45 \%$ DW injection would reduce NOx output $60 \%$, yet not increase SFC over the baseline condition. 


\section{CONCLUSION}

This paper describes the modeling of water injection as a practical NOx reduction technology for DI Diesel engines. The water injection model was verified against experimental high temperature spray data and was used to gain additional insight into multiple liquid spray phenomena. It was shown that the latent heat of vaporization was the physical property that caused the liquid in a fully mixed spray of fuel and water to penetrate further than a spray of the same volume of fuel alone.

The bomb simulation of a completely mixed fuel-water spray showed that the liquid spray tip penetration increases by approximately $35 \%$ due mostly to the high latent heat of the water. Vapor penetration is not changed as much as the liquid penetration, however the fuel penetration along the axis increases with the presence of water due to an increase in the jet momentum.

Engine calculations showed very good agreement with pressure, ignition delay and SFC for both nozzles considered, and trends for PM and NOx emissions were accurately predicted for both loads under consideration. For $44 \%$ loads, SFC, PM and NOx emissions decrease, while for $86 \%$ loads only NOx emissions decrease. The calculations showed that the main mechanism behind the NOx and soot reduction is lower peak temperatures in the combustion region that reduce the formation rate of the pollutants. Advancing the injection timing allows significant decreases in SFC, PM and NOx for $44 \%$ loads, and large decreases in PM and NOx but with a small increase in fuel consumption for $86 \%$ loads.

The mechanism for the lower temperatures with water injection is that both the vaporization of liquid water and an increase in specific heat of the gas around the flame. If too much water is used, the volume of injected liquid increases to the point where the injection duration is too long and the soot emissions increase. DW injection has advantages over other water injection techniques, namely fumigation and emulsified fuels, however is expensive to implement. Additionally, further study is needed to find the best fuel/water percentage for various operating conditions.

The challenges facing this technology are difficult to overcome, however if fuel prices increase and emissions regulations continue to tighten, the direct water injection technique could become a viable option for DI Diesel engines in comparison to DeNOx catalysts or alternative NOx aftertreatments.

\section{ACKNOWLEDGMENTS}

This work was supported by DaimlerChrysler AG, Stuttgart. The authors thank Dr. Ron Donahue and Professor David Foster of the Engine Research Center at UW-Madison for helpful discussions. Special thanks also go to Helmut Gildein and Gerhard König from DaimlerChrysler research.

\section{REFERENCES}

1. Amsden, A. A., O'Rourke, P. J., and Butler, T. D., "KIVA-II: A Computer Program for Chemically Reactive Flows with Sprays" Los Alamos National Laboratory Report No. LA-11560-MS, 1989.

2. Curran, H. J., Gaffure, P., Pitz, W. J., and Westbrook, C. K., "A Comprehensive Modeling Study of N-Heptane Oxidation," Combustion and Flame, vol.114, pp.149-177, 1998.

3. Dittrich, P., Wirbeleit, F. Willand, J. and Binder, K., "MultiDimensional Modeling of the Effect of Injection Systems on DI Diesel Engine Combustion and NO-Formation", SAE 982585, 1998

4. Han, Z., Uludogan, A., Hampson, G.J., and Reitz, R. D., "Mechanism of Soot and NOx Emission Reduction Using Multiple--Injection in a Diesel Engine", SAE 960633, 1996.

5. Kazakov, A. and Foster, D., "Modeling of Soot Formation During DI Diesel Combustion Using a Multi-Step Phenomenological Model", SAE 982463, 1998.

6. Patterson, M.A., Kong, S.C., Hampson, G.J., and Reitz, R. D., "Modeling the Effects of Fuel Injection Characteristics on Diesel Engine Soot and NOx Emissions", SAE 940523, 1994.

7. Reitz, R. D., "Modeling Atomization Processes in High-Pressure Vaporizing Sprays", Atomization and Spray Technology, 3, 1987.

8. Rutland, C.J., Eckhause, J., Hampson, G., Hessel, R., Kong, S., Patterson, M., Pierpont, D., Sweetland, P., Tow T., and Reitz, R. D., "Toward Predictive Modeling of Diesel Engine Intake Flow, Combustion, and Emissions", SAE 941897, 1994.

9. Renner, G., Maly, R.R., "Moderne Verbrennungsdiagnostik fur die dieselmotorische Verbrennung, in Dieselmotorentechnik" 98, Expert Verlag, editor U. Essers [Hrsg.), 1998.

10. Takasaki, K., "Improvement of Diesel Combustion with Stratified Fuel/Water Injection System", MTZ Motortechnische Zeitschrift 59 (1988)

11. Schwarz, V., König, G., Dittrich, P. and Binder, K., "Analysis of Mixture Formation, Combustion and Pollutant Formation in HD Diesel Engines using Modern Optical Diagnostics and Numerical Simulation", SAE 1999-013647, 1999

12. Wirbeleit, F., Enderle, CH., Lehner, W., Raab, A., Binder, K., "Stratified Diesel Fuel--Water--Diesel Fuel Injection Combined with EGR -- The Most Efficient In--Cylinder NOx and PM Reduction Technology", SAE 972962, 1997 